\title{
Effects of artificial damage on the branching pattern of Nothofagus dombeyi (Nothofagaceae)
}

\author{
Javier Guido PUNTIERI ${ }^{\mathrm{a}, \mathrm{b} *}$, Marina STECCONI ${ }^{\mathrm{b}}$, Cecilia BRION $^{\mathrm{a}}$, Camilo MAZZINI ${ }^{\mathrm{b}}$, Javier GROSFELD ${ }^{\mathrm{a}, \mathrm{b}}$ \\ a Departamento de Botánica, Universidad Nacional del Comahue, Quintral 1250, 8400, Bariloche, Argentina \\ ${ }^{\mathrm{b}}$ Consejo Nacional de Investigaciones Científicas y Técnicas, Argentina
}

(Received 18 November 2004; accepted 29 June 2005)

\begin{abstract}
The effects of artificial damage on the branching pattern were studied for a natural population of Nothofagus dombeyi trees. In four independent experiments, leaves, buds, distal internodes and/or nodes were clipped from main-branch shoots. The sizes of shoots close to the site of damage were compared with those of control shoots. None of the treatments induced the outbreak of dormant proventitious buds or adventitious buds. Organ clipping from shoots in winter or early spring resulted in moderate increases in the growth of shoots close to the site of damage. The removal of a distal shoot in late spring caused an increase in the growth of a neighbour shoot. The size of the largest shoot relative to that of the other shoots developed on the same parent shoot seems to depend on the tree concerned.
\end{abstract}

branching pattern / herbivory / plant architecture / shoot growth / compensatory response

Résumé - Effets de facteurs traumatiques sur le mode de ramification de Nothofagus dombeyi (Nothofagaceae). Les effets de traumatismes artificiels sur le processus de ramification ont été étudiés sur une population naturelle d'arbres de Nothofagus dombeyi. Dans quatre experimentations indépendantes, l'apex de l'axe, les feuilles et/ou les bourgeons axillaires de pousses annuelles sur des rameaux principaux ont été coupés et la modalité de ramification des pousses traitées comparée avec celle de pousses témoins. Aucun des traitements appliqués n'a induit le débourrement de bourgeons proventifs dormants ou adventifs. Le prélèvement d'organes pendant l'hiver ou le débourrement printanier n'a stimulé qu'une augmentation modérée de la taille des pousses les plus proches du site de traumatisme. Le sectionnement de l'apex d'une pousse à la fin du printemps induit l'augmentation de la taille d'une pousse voisine. Un effet «arbre » est mis en évidence dans la taille de la pousse la plus grande relativement à la taille des autres pousses développées sur la même pousse d'origine.

mode de ramification / herbivore / architecture des plants / réponse compensatoire

\section{INTRODUCTION}

The aerial structure of most woody plants consists of a system of branched axes. The branching patterns resulting from variations in the size and spatial arrangement of the branches derived from each axis have been interpreted as different ways of optimising light capture while reducing self-shading [14, 20-22, 28, 29, 32, 38, 45]. Several endogenous factors, including hormonal interactions, resource sink strength and allocation, hydraulic conductance and position on the tree and age of the branching system are known to be involved in an axis' branching pattern $[4,9,10,13,25,26,36,48,53,54]$. However, a number of exogenous traumatic factors such as stressful environmental conditions and herbivory may interfere with the expression of the endogenously determined branching pattern. The existence of plant responses compensating or overcompensating in terms of biomass production after biomass losses caused by herbivory has been repeatedly demonstrated, mainly for herbaceous plants [24, 33]. On the contrary, little is known about the extent to which traumatic factors affect the branching pattern of woody plants and the capacity of these plants to restore this pattern after a trauma $[4,5,8,23,31,33]$. Two major reasons for this information deficiency are the high architectural complexity and slow short-term response to damage of woody plants as compared to those of herbaceous species [24]. These difficulties may be circumvented with a deep knowledge of a species' architecture and an adequate selection of structural modules repeated in plants of the same species at a given developmental stage. One such modules for species from temperate regions consists of a parent shoot extended in one growing season (usually spring-summer) and a series of offspring shoots derived from buds of the parent shoot in the following growing season [36, 44].

Nothofagus dombeyi (Mirb.) Oerst. (Nothofagaceae) is a relatively abundant evergreen, forest tree species from temperate South America. The basic architecture of this species has been studied in recent years $[39,42,43,45]$. By mid-summer, at the end of its extension period, each shoot of $N$. dombeyi bears one axillary bud at all but its most proximal nodes (sylleptic branches may be borne by the most vigorous shoots, usually

* Corresponding author: jpuntier@crub.uncoma.edu.ar 
those of the trunk). A terminal bud may also develop but spontaneous apex deaths are very frequent [39]. Each bud of a shoot generates an offspring shoot in the spring following that in which the parent shoot extended; the size of the offspring shoots derived from a common parent shoot usually decreases as the parent shoot's proximal end is approached, as in many other tree species $[6,9,39,41,42,45]$. Insects belonging to the families Geometridae, Agromicidae, Cerambycidae, Chrysomelidae and Curculionidae may damage buds, leaves and shoots of Nothofagus species [30, 34, 47]. Other exogenous factors such as drought or frost may allegedly traumatise the distal end of shoots [39]. To our knowledge, the extent to which traumas acting on different organs and at different times of the year affect the branching pattern of Nothofagus trees has not been investigated. In the present study we report the results of four experiments in which artificial damage was applied to main-branch shoots of $N$. dombeyi, simulating naturally occurring damage.

The main objective of the present study was to assess the effects of traumatic factors on the branching pattern of $N$. dombeyi through artificial interventions on shoots. The secondary objectives were the evaluations of differences in the branching pattern of shoots subject to bud, leaf and shoot-apex damage, and differences in the branching pattern of shoots after damage occurring at different stages of the yearly growth cycle.

\section{MATERIALS AND METHODS}

\subsection{Sampling site and trees}

The sampling site lies within the Nahuel Huapi National Park, Argentina, $25 \mathrm{~km}$ south of San Carlos de Bariloche city ( $41^{\circ} 10^{\prime} \mathrm{S}$, $71^{\circ} 10^{\prime} \mathrm{W}, 850 \mathrm{~m}$ altitude). The mean annual precipitation is about $1000 \mathrm{~mm}$ and the mean temperatures for the warmest and the coolest months are, respectively, $14.0^{\circ} \mathrm{C}$ and $2.4{ }^{\circ} \mathrm{C}$ [12]. The soil in this area derived from volcanic ash [49]. A natural population of over 500 young $N$. dombeyi trees (18-25 years old, 5-9 m high), developed along $2 \mathrm{~km}$ of roadside after road construction, was selected for this study. At the time of this study, the trees were at the developmental stage characterised by a well-defined and vigorously growing vertical trunk and horizontal or slanted main branches derived from the trunk [39]. The experiments were performed on sets of randomly chosen, healthylooking trees of the population. Each tree selected for one experiment was tagged so as to avoid including it in subsequent experiments. In all experiments, horizontal main branches derived at 1.5 to $2.5 \mathrm{~m}$ high from the trunk were labelled. Fully extended parent shoots located at the distal end of the labelled main branches were chosen as sample units in all experiments. For each tree, all parent shoots selected had derived from different shoots. At the beginning of each experiment, each main-branch parent shoot selected consisted of a stem with 1028 nodes, and one leaf at each node. The large majority of these shoots were devoid of terminal bud, which does not alter the branching pattern of the axis; in this species, the development of a relay shoot from the most distal axillary bud of the parent shoot usually gives rise to a pseudo-monopodial branching system [6, 39]. Depending on the experiment, each node of a parent shoot was bearing, at the beginning of the experiment, either an axillary bud or a growing offspring shoot (Fig. 1).

\subsection{Experimental design}

\subsubsection{Experiments 1, 2 and 3}

In each of these experiments a complete-block design [50] was applied, considering each tree as a block and leaving unaltered one of the labelled parent shoots of each tree (control $=$ t.0; Fig. 1 ). These experiments differed in the time of the year in which manipulations were applied to shoots (Fig. 2).

In experiment 1 , six parent shoots extended in the 1999-2000 growing season were labelled on each of thirty trees (Figs. 1 and 2) and the following treatments applied in August 2000 (mid-winter), before the beginning of the 2000-2001 growing season: (t.1) clipping (with surgical scissors) of the distal portion of the shoot from the fourth internode counted from the parent shoot's distal end; (t.2) clipping of the four most distal buds of the parent shoot; (t.3) clipping of the four most distal leaves (at the petiole base) of the parent shoot; (t.4) clipping of the two largest shoots extended at the same time and from the same shoot as the labelled parent shoot (brother shoots); (t.5) stem girdling, with a surgery blade, at the fourth internode counted from the parent shoot's distal end (girdling was repeatedly tested on other trees and longitudinal stem sections were observed under light microscope so as to make sure that the ring cut interrupted the phloem cylinder). All treated parent shoots and the control were harvested in March 2001, after the end of the 2000-2001 growing season (Fig. 2).

In experiment 2 , two parent shoots of each of thirty-one trees were labelled in November 2001, by the time of spring bud-burst (Fig. 2). At that time, the four most distal nodes of one of the labelled parent shoots per tree were cut off (t.1, like that of experiment 1; Fig. 1). The second labelled parent shoot of each tree was left unaltered (t.0). In March 2002, after verifying that all offspring shoots had stopped their extension, all labelled parent shoots were harvested.

In experiment 3 , five parent shoots were selected and labelled in each of thirty-five trees in December 2003 (late spring), when offspring shoots derived from axillary buds of the parent shoots were at the peak of their length growth. At that time, one of the following treatments was applied to the most distal offspring shoot of each labelled parent shoot (Fig. 1): (t.1) clipping of the apex, including all folded leaves; (t.2) clipping of the four most distal axillary buds and subtending leaves ${ }^{1}$; (t.3) clipping of the four most distal unfolded leaves; (t.4) clipping of the complete shoot. Labelled parent shoots were harvested in late March 2004, after the end of offspring shoot extension (Fig. 2).

For experiments 1, 2 and 3, the nodes of each parent shoot were numbered correlatively starting at the most distal node from which an offspring shoot had developed (Fig. 1). Nodes whose axillary buds had been removed experimentally (treatment 2 of experiments 1 and 3) were not accounted for in node numbering. Stem basal diameter (to the nearest $0.1 \mathrm{~mm}$ with callipers), length (to the nearest $1 \mathrm{~mm}$ with a ruler) and number of nodes were registered for parent shoots and offspring shoots. Those parent shoots for which at least one offspring shoot was damaged by a factor other than those experimentally applied, was excluded from the analyses.

\subsubsection{Experiment 4}

In this experiment, the effects of bud and leaf removal on the extent of organ differentiation in nearby undamaged buds were assessed. The four most distal axillary buds and leaves of seven growing mainbranch shoots of a single tree were clipped in December 2003, without injuring the growing shoot apex (Fig. 2). In May 2004, after the end of shoot extension and organ differentiation, all treated and 11 untreated main-branch shoots of the same tree were harvested, and

\footnotetext{
${ }^{1}$ At that stage of bud development, bud clipping without causing damage to its subtending leaf was virtually impossible.
} 

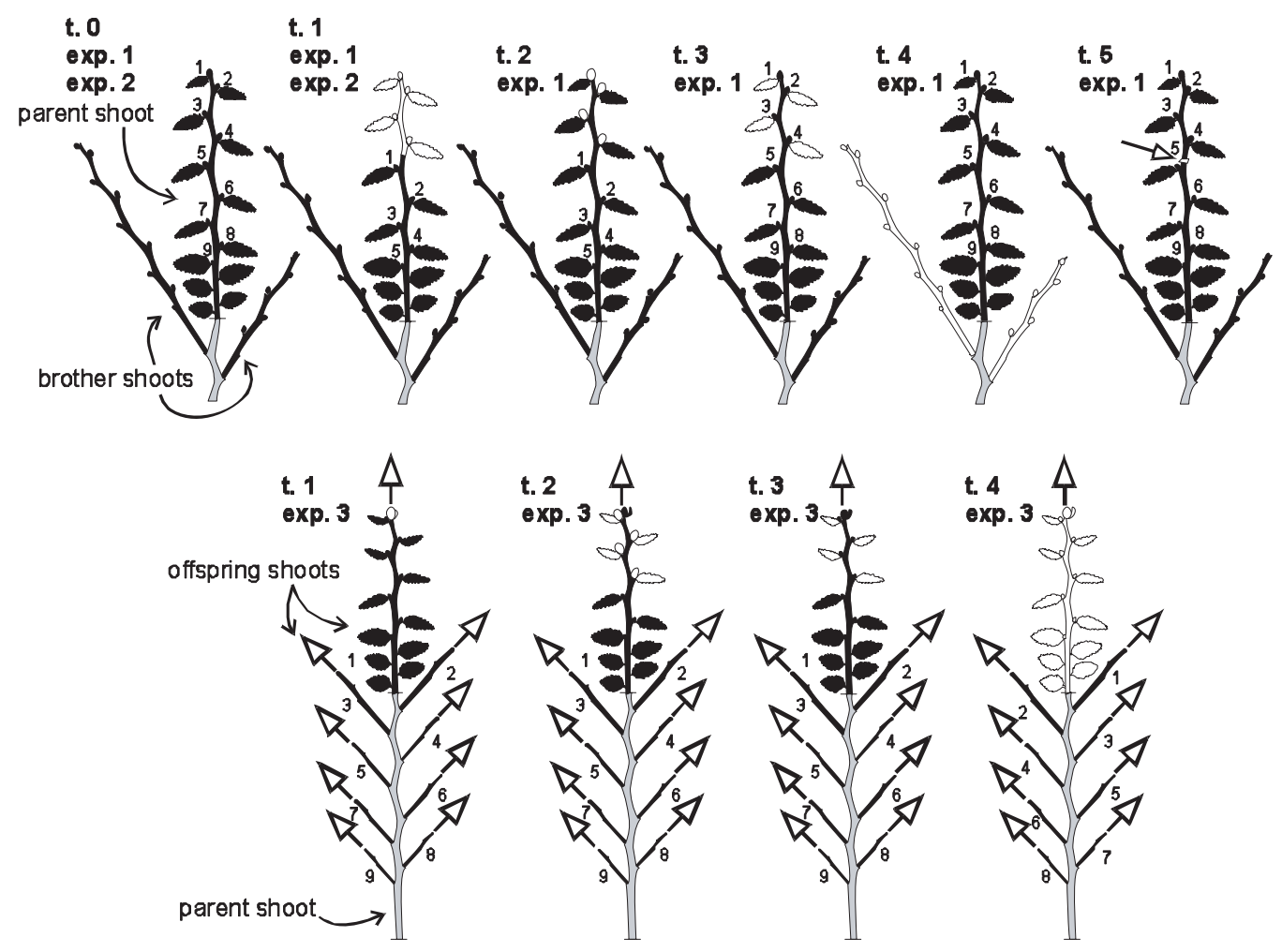

Figure 1. Diagrammatic representation of distal ends of Nothofagus dombeyi main branches and the treatments applied in experiments 1 (t.0 - t.5, upper row), 2 (t.0 and t.1, upper row) and 3 (t.1 - t.4, lower row). In all cases, the removed organs are white filled. Leaves were drawn only for parent shoots of upper drawings and one offspring shoot of each lower drawing. The distal-to-proximal node numbering used here is indicated for each diagram. Upper drawings (parent shoots and brother shoots are black filled): t.0: control, t.1: clipping of distal portion, t.2: clipping of distal buds, t.3: clipping of distal leaves, t.4: clipping of brother shoots, t.5: stem girdling (girdling position indicated with an arrow). Lower drawings (offspring shoots are black filled and parent shoots are grey filled): t.1: clipping of the apex, t.2: clipping of distal buds and leaves, t.3: clipping of distal leaves, t.4: clipping of distal offspring shoot. A white arrow indicates that the corresponding shoot was growing at the time the experiment was started.

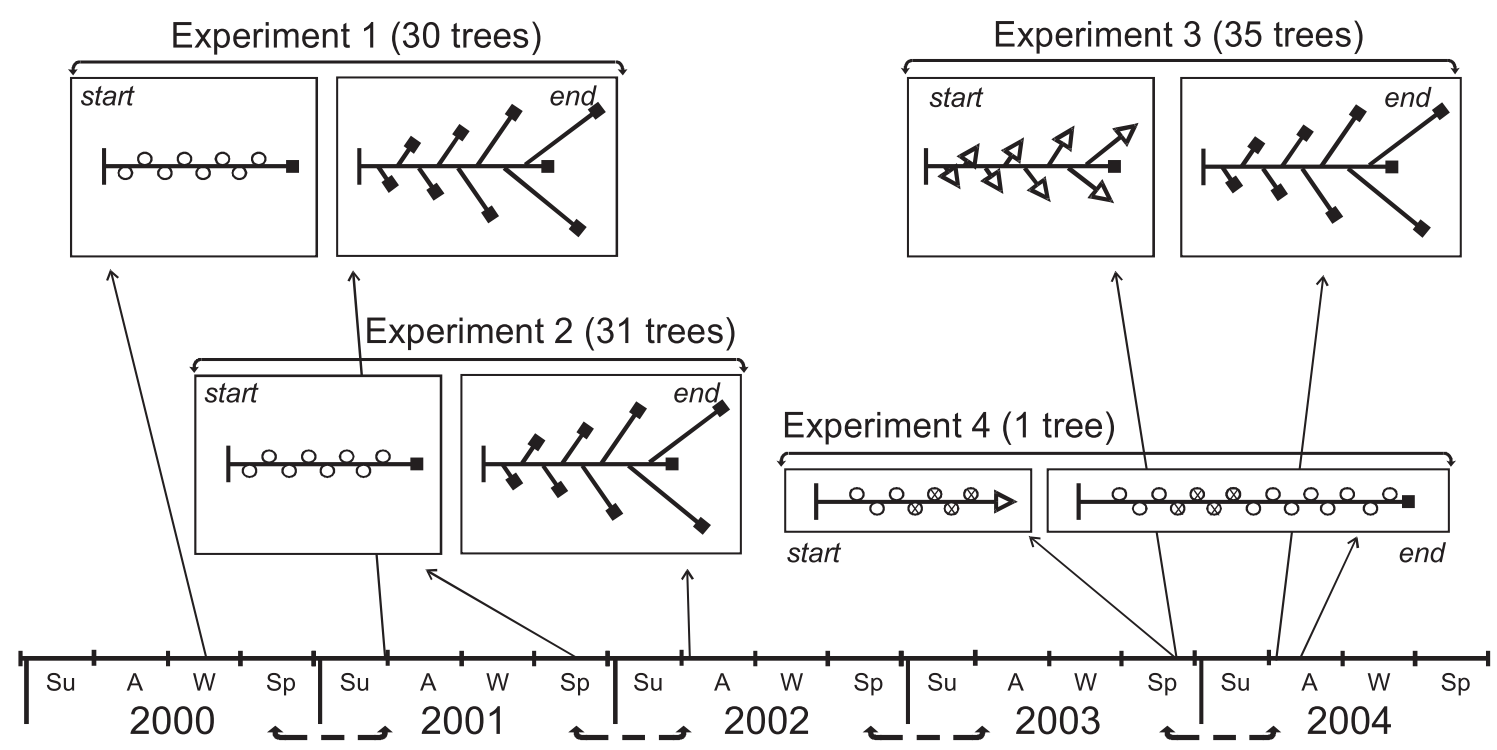

Figure 2. Scheme showing the main-branch shoots of $N$. dombeyi at the beginning and the end of experiments $1,2,3$ and 4 on a time scale: years 2000 to 2004; Su: summer, A: autumn, W: winter, Sp: spring; dashed arrows: growing season. White circle: axillary bud. Crossed circle: removed axillary bud. White arrow: growing shoot. Square-headed line: fully-extended shoot. Numbers in brackets indicate the number of trees selected for each experiment. 
Table I. Diameter, length, number of nodes (mean \pm s.e., $N$ in brackets) of parent shoots of each treatment of experiments 1,2 and 3.

\begin{tabular}{|c|c|c|c|}
\hline & Diameter (mm) & Length $(\mathrm{cm})$ & Nodes \\
\hline \multicolumn{4}{|c|}{ Experiment 1} \\
\hline t.0 & $2.6 \pm 0.08$ & $14.8 \pm 0.81$ & $15.8 \pm 0.64(24)$ \\
\hline t. 1 & $2.6 \pm 0.11$ & $14.5 \pm 0.89$ & $15.4 \pm 0.66$ \\
\hline t. 2 & $2.6 \pm 0.08$ & $14.5 \pm 0.94$ & $16.2 \pm 0.65(24)$ \\
\hline t. 3 & $2.8 \pm 0.10$ & $14.7 \pm 0.92(25)$ & $15.8 \pm 0.63(25)$ \\
\hline t. 4 & $2.5 \pm 0.09$ & $13.6 \pm 0.82(24)$ & $15.9 \pm 0.78$ \\
\hline t.5 & $2.6 \pm 0.09$ & $14.9 \pm 0.79(23)$ & $15.9 \pm 0.60$ \\
\hline \multicolumn{4}{|c|}{ Experiment 2} \\
\hline t.0 & $3.0 \pm 0.07$ & $16.0 \pm 0.79(30)$ & $16.9 \pm 0.76(30)$ \\
\hline t. 1 & $2.9 \pm 0.07$ & $15.3 \pm 0.64$ & $16.4 \pm 0.66$ \\
\hline \multicolumn{4}{|c|}{ Experiment 3} \\
\hline t. 0 & $4.7 \pm 0.18$ & $21.7 \pm 2.07$ & $18.9 \pm 1.09$ \\
\hline t. 1 & $4.1 \pm 0.20(31)$ & $19.0 \pm 2.01$ & $17.1 \pm 0.92$ \\
\hline t. 2 & $4.4 \pm 0.22(35)$ & $21.0 \pm 2.01$ & $19.6 \pm 1.17(35)$ \\
\hline t. 3 & $4.4 \pm 0.25$ & $20.2 \pm 2.50(35)$ & $18.3 \pm 1.12$ \\
\hline t. 4 & $4.2 \pm 0.21$ & $19.1 \pm 1.84$ & $18.0 \pm 1.08$ \\
\hline
\end{tabular}

fixed in $96 \%$ ethanol for two weeks. The buds of these shoots were numbered in a distal-to-proximal sequence and dissected under stereomicroscope (Olympus SZH10, up to $70 \times$ ), so as to determine the number of leaf primordia of each bud.

\subsection{Data analyses}

For each treatment of experiments 1, 2 and 3, the mean diameter, length and number of nodes of offspring shoots in each position were computed. Whenever an offspring shoot had developed branches during its extension, its length and number of nodes were computed, respectively, as the sum of the lengths and the sum of the nodes of its main axis and its branches. For each parent shoot, the thickest offspring shoot was identified and the maximum diameter ratio (MDR) was computed as:

MDR $=$ [diameter of the thickest offspring shoot $] /$ [mean diameter for all other offspring shoots].

Following the same procedure, the maximum length ratio (MLR) was computed as:

MLR $=$ [length of the longest offspring shoot] / [mean length for all other offspring shoots],

and the maximum number of nodes ratio (MNR) as:

MNR $=$ [number of nodes of the offspring shoot with more nodes $] /$ [mean number of nodes for all other offspring shoots].

The sums of diameters ( $\Sigma$ diameters), lengths ( $\Sigma$ lengths) and numbers of nodes ( $\Sigma$ nodes) of all offspring shoots were calculated for each parent shoot.

Analyses of variance (ANOVA) [50] were performed within experiments 1,2 and 3 to assess the effect of treatments (fixed factor) and trees (random factor) on each of the following variables: (1) position on the parent shoot of the most proximal offspring shoot, (2) diameter of the thickest offspring shoot, (3) length of the longest offspring shoot, (4) number of leaves of the largest offspring shoot, (5) MDR, (6) MLR, (7) MNR, (8) $\Sigma$ diameters (9) $\Sigma$ lengths and (10) $\Sigma$ nodes of offspring shoots. Data $\log _{\mathrm{e}}$-transformation was applied for all variables so as to render distributions normal (graphic test) [50]. Bonferroni's correction was applied for significance levels to account for the number of comparisons performed. For experiment 3, treated offspring shoots of treatments 1,2 and 3 and the most distal offspring shoots of treatment 4 and control parent shoots were compared with respect to: presence of axillary branches (Chi-square tests), diameter, length and number of nodes (ANOVA). The total number of leaf primordia of all buds of treated and control shoots of experiment 4 were compared with a Student's $t$ test. All statistical analyses were performed with the Minitab 7.1 software [35].

Throughout the following text, the term "size" will be used collectively in reference to the diameter, length and number of nodes of shoots.

\section{RESULTS}

\subsection{Parent shoots}

Within experiments 1,2 and 3, parent shoots of all treatments had a similar size; those of experiment 3 were slightly larger than those of the other two experiments (Tab. I). Offspring shoots developed from all nodes except, on average, the six nodes closest to the parent shoot's proximal end and those nodes experimentally deprived of axillary bud. Treatments did not affect the position of the most basal offspring shoot on each parent shoot (Tab. II). For experiments 1 and 3, the position of the most basal offspring shoot depended on the tree concerned.

\subsection{Offspring shoots}

The size of offspring shoots tended to be highest for the most distal positions on the parent shoots of all treatments of experiments 1, 2 and 3 and to decrease gradually towards the proximal end of the parent shoot (Fig. 3). Variations in diameter among offspring shoots followed an approximately linear tendency for all experiments (Fig. 3). On the other hand, variations 
A. Experiment 1
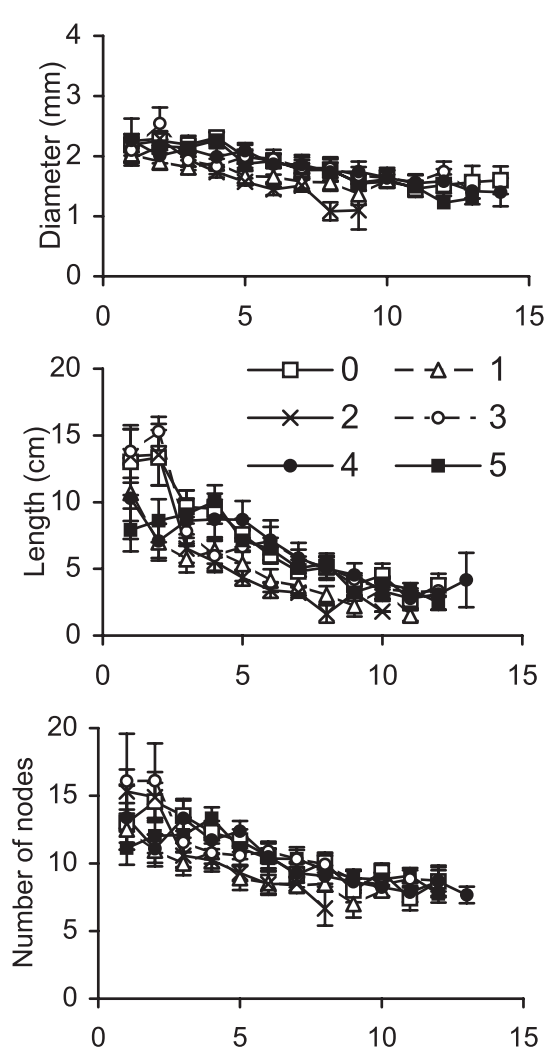

B. Experiment 2
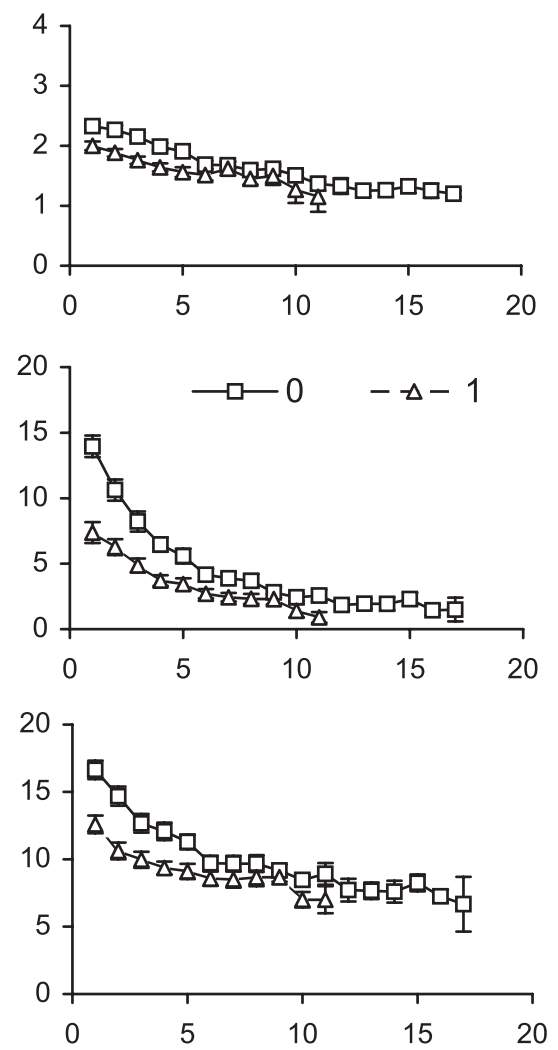

C. Experiment 3


Position on the parent shoot

Figure 3. Mean ( \pm s.e.) diameter, length and number of nodes of offspring shoots derived from parent shoots assigned to different treatments of experiments 1 (A), 2 (B) and 3 (C; see text for details), according to the position of the offspring shoot numbered from the parent shoot's distal end.

Table II. Results of two-way ANOVAs (Fisher's test, $F$ ) assessing the effects of treatments and trees on the position of the most proximal offspring shoot, the diameter, length and number of nodes of the largest (max.) offspring shoot, the MDR, MLR and MNR, and the sums of offspring-shoot diameters, lengths and numbers of nodes for experiments 1,2 and 3 (see text for details). *** $p<0.001, * * p<0.01, * p<0.05$, ns: $p>0.05$.

\begin{tabular}{|c|c|c|c|c|c|c|c|c|c|c|c|c|}
\hline & \multicolumn{4}{|c|}{ Experiment 1} & \multicolumn{4}{|c|}{ Experiment 2} & \multicolumn{4}{|c|}{ Experiment 3} \\
\hline & \multicolumn{2}{|c|}{ Treatment } & \multicolumn{2}{|c|}{ Tree } & \multicolumn{2}{|c|}{ Treatment } & \multicolumn{2}{|c|}{ Tree } & \multicolumn{2}{|c|}{ Treatment } & \multicolumn{2}{|c|}{ Tree } \\
\hline & $F$ & $p$ & $F$ & $p$ & $F$ & $p$ & $F$ & $p$ & $F$ & $p$ & $F$ & $p$ \\
\hline Position & 0.4 & ns & 2.4 & $* *$ & 0.7 & $\mathrm{~ns}$ & 1.4 & ns & 1.4 & ns & 1.9 & $* *$ \\
\hline Max. diameter & 0.8 & $\mathrm{~ns}$ & 2.2 & $* *$ & 25.4 & $* * *$ & 1.4 & $\mathrm{~ns}$ & 0.9 & ns & 2.6 & $* * *$ \\
\hline Max. length & 0.8 & ns & 1.8 & $*$ & 34.2 & $* * *$ & 1.0 & ns & 1.6 & ns & 3.9 & $* * *$ \\
\hline Max. number of nodes & 0.7 & ns & 1.7 & $*$ & 52.1 & $* * *$ & 3.5 & $* *$ & 1.6 & ns & 2.9 & $* * *$ \\
\hline MDR & 0.4 & $\mathrm{~ns}$ & 3.1 & $* * *$ & 11.0 & $* * *$ & 1.7 & $\mathrm{~ns}$ & 1.3 & ns & 2.3 & $* * *$ \\
\hline MLR & 1.3 & $\mathrm{~ns}$ & 1.5 & $\mathrm{~ns}$ & 18.7 & $* * *$ & 1.3 & $\mathrm{~ns}$ & 5.0 & $* *$ & 4.1 & $* * *$ \\
\hline MNR & 0.2 & $\mathrm{~ns}$ & 1.5 & $\mathrm{~ns}$ & 30.9 & $* * *$ & 2.2 & $*$ & 2.4 & $*$ & 3.0 & $* * *$ \\
\hline$\Sigma$ diameters & 7.8 & $* * *$ & 2.2 & $* *$ & 77.4 & $* * *$ & 3.3 & $* *$ & 1.3 & ns & 7.1 & $* * *$ \\
\hline$\Sigma$ lengths & 3.2 & $* *$ & 1.4 & $\mathrm{~ns}$ & 56.1 & $* * *$ & 2.2 & $*$ & 0.7 & ns & 7.9 & $* * *$ \\
\hline$\Sigma$ nodes & 7.3 & $* * *$ & 2.4 & $* *$ & 85.7 & $* * *$ & 4.1 & $* *$ & 0.9 & ns & 8.8 & $* * *$ \\
\hline
\end{tabular}





Figure 4. Mean (+ s.e.) diameter (A), length (B) and number of nodes (C) of the largest offspring shoot developed from parent shoots for experiments 1 (black bars), 2 (grey bars) and 3 (white bars). Treatment $0=$ control. See text for descriptions of treatments.

in length and number of nodes of offspring shoots tended to diverge from linearity, and the extents of these divergences depended on the treatment and experiment concerned (Fig. 3). For experiment 1 , the size of the largest offspring shoot per parent shoot and the MDR, MLR and MNR were not affected by the treatments (Tab. II; Figs. 4 and 5). In the case of experiment 2, the largest offspring shoots of t.1 were significantly smaller (in diameter, length and number of nodes), both in absolute and relative terms, than those of t.0 (Tab. II; Figs. 4 and 5). For experiment 3, although the cutting of the distal offspring shoot (t.4) tended to increase the mean size of the largest offspring shoot (Figs. 4 and 5), the difference between this and the other treatments reached a statistically significant level only for the MLR and the MNR (Tab. II; Figs. 4B, 4C, 5B and 5C).

The $\Sigma$ diameters, $\Sigma$ lengths and $\Sigma$ nodes of offspring shoots per parent shoot were lower for t. 1 and t. 2 than for the other treatments of experiment 1 and lower for t. 1 than for t. 0 of experiment 2 (Fig. 6 and Tab. II). None of these sums was affected by the treatments of experiment 3 . The $\Sigma$ diameters and $\Sigma$ nodes per parent shoot were related to the tree concerned in all three experiments. The $\Sigma$ lengths was also related to the tree in experiments 2 and 3 but not in experiment 1 (Tab. II).

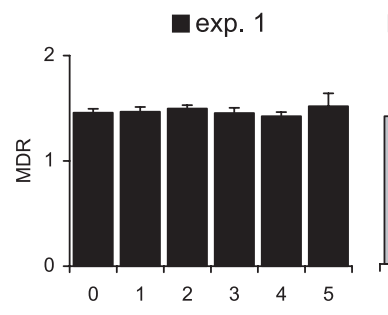

$\square \exp .2$

$\square \exp .3$

A

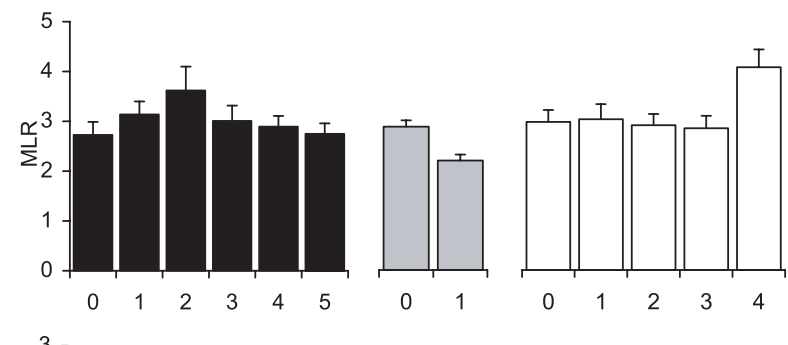

B



C

Figure 5. Mean (+ s.e.) diameter (A), length (B) and number of nodes (C) of the largest offspring shoot relative to the mean diameter, length and number of nodes of the other offspring shoots (MDR, MLR and MNR, respectively) for experiments 1 (black bars), 2 (grey bars) and 3 (white bars). Treatment $0=$ control.

Between four and ten offspring shoots per treatment of experiment 3 developed at least one axillary branch, but the proportion of branched offspring shoots proved not to be different between treatments $\left(\chi^{2}=3.1, p>0.1\right)$. The diameter and number of nodes of treated offspring shoots of t.1, t.2 and t.3 of experiment 3 were similar to those of the most distal offspring shoot of t.0 and t.4 $(F=1.4$ and $F=2.1$, respectively, $p>0.05)$. For this experiment, distal offspring shoots corresponding to t. 4 were, on average, longer than treated offspring shoots of t.1, t.2 and t.3 and the distal offspring shoots of t.0 $(F=2.4, p<0.05)$.

\subsection{Bud composition}

Treated shoots of experiment 4 did not develop axillary organs in the nodes from which buds were removed. Those buds developed in distal positions after the removal of distal buds and leaves included, on average, more leaf primordia than buds in similar positions of untreated shoots, whereas buds located proximally relative to the nodes whose buds had been removed had less primordia than proximal buds of control shoots (Fig. 7). The sum of leaf primordia of all buds of treated shoots was similar to that of control shoots $(t=0.7, p=0.52)$. 

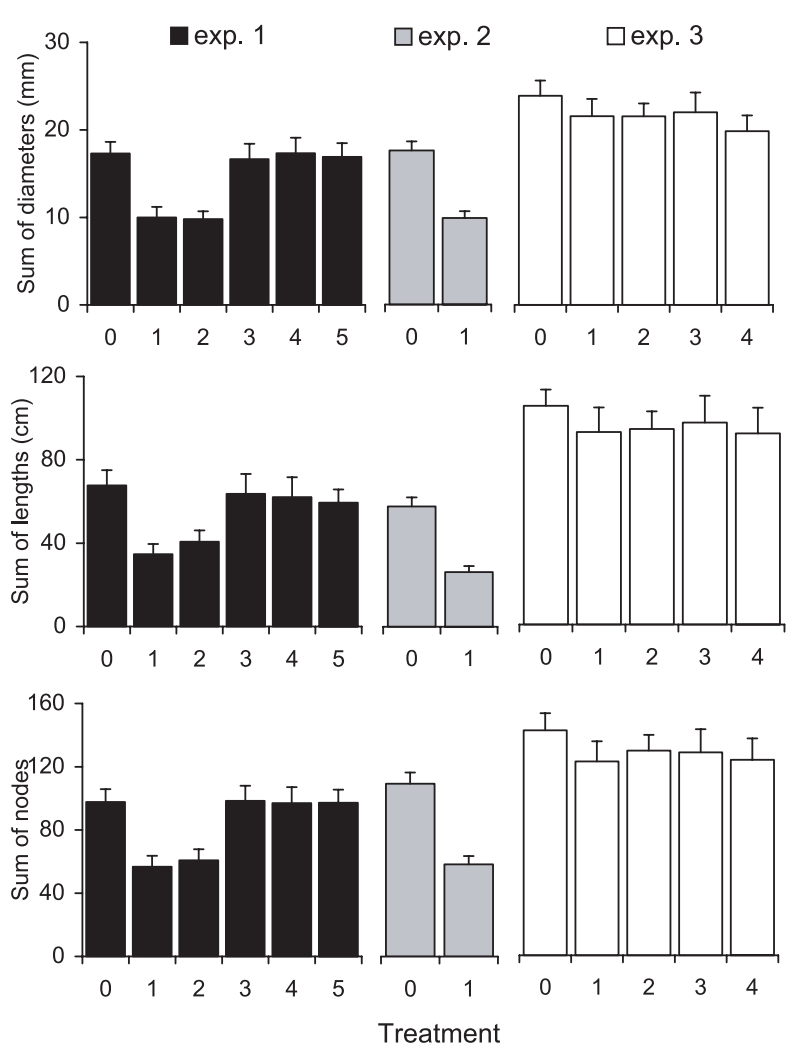

Figure 6. Mean (+ s.e.) sum of diameters (A), lengths $(\mathbf{B})$ and numbers of nodes $(\mathbf{C})$ of offspring shoots developed from parent shoots of experiments 1 (black bars), 2 (grey bars) and 3 (white bars). Treatment $0=$ control.

\section{DISCUSSION}

\subsection{Resilience to damage of $N$. dombeyi branching systems}

In $N$. dombeyi trees, like in many other tree species, the branching system consisting of a parent shoot extended in one year and a cohort of offspring shoots extended a year later is characterized by a gradient of increasing offspring shoot size towards the distal end of the parent shoot [42, 45, 46]. At least for the main branches of young $N$. dombeyi trees, this gradient seems to be resilient to traumatic factors acting either on the distal portion of a parent shoot before the extension of its offspring shoots (experiments 1 and 2) or on the offspring shoots themselves during their extension (experiment 3 ). Therefore, it could be proposed that, whatever the physiological bases of size differences among offspring shoots, they are not under the exclusive control of the distal end of their parent shoot.

The activation of dormant proventitious buds and the development of adventitious buds, cited as usual responses to damage for other species $[3,7,11,18,19,40]$, were not detected in any of the experiments of the present study. Shoots of Nothofagus spp. have tiny axillary buds close to their proximal end. These proventitious buds do not develop into shoots one year after their inception, unlike more distal axillary buds. Some studies have proposed that these proximal buds might form a
Bud composition

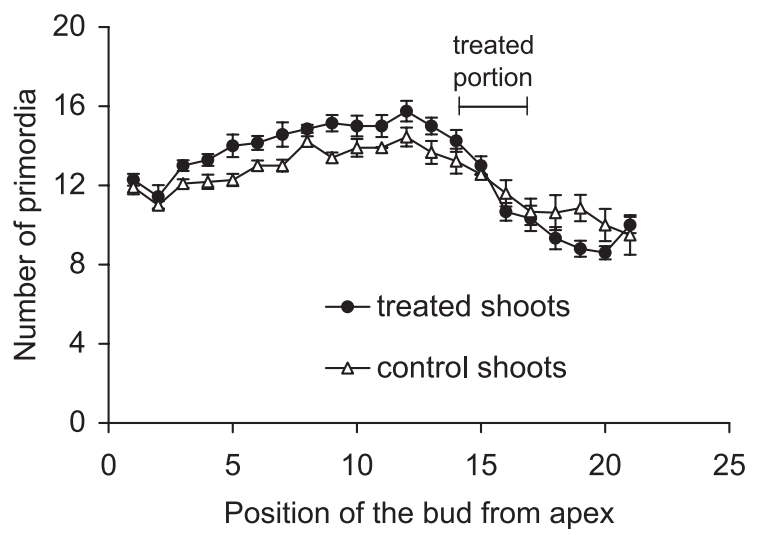

Figure 7. Mean (+ s.e.) number of nodes of buds in seven shoots for which bud removal was applied (black circles) and number of nodes of buds of 11 control shoots (white triangles) of the same tree. The portion of treated shoots from which buds were removed is indicated with a line.

"bud bank" able to regenerate the branching system after a major damage to their parent shoot [42, 44, 51]. According to the present study, this would not be the case when damage involves the distal nodes of $N$. dombeyi shoots, since none of the treatments applied here affected the position of the most proximal branches on shoots. On the other hand, some kinds of traumas acting on a parent shoot at specific periods of the year caused the sum of the sizes of all its branches and/or size differences between distal and proximal branches to be lower than those observed for non-traumatised parent shoots.

\subsection{Damage to growing shoots}

The size of offspring shoots developed from a parent shoot is controlled at several stages [54], the first of which is the differentiation of organs in the buds from which the offspring shoots would eventually develop (i.e. preformation). The physiological processes underlying differences in preformation among buds are not well understood, although competition for resources and hormonal interactions seem to be involved [9, 10]. The experimental removal of axillary buds differentiating at the distal nodes of an extending parent shoot did not affect the final length and number of nodes of this shoot or the total number of organs differentiated in its buds at the end of its growth period (experiment 4). In other words, the loss of primordial organs due to exogenous factors was compensated by the development of more primordia in other buds. The positive effect of bud clipping on the preformation of distal buds and its negative effect on the preformation of proximal buds would cause an increase in the gradient of the number of preformed leaves between distal and proximal branches eventually developed from the damaged shoot. This result should be regarded with caution considering the significant tree effect detected in most comparisons of experiments 1, 2 and 3 (Tab. II) and the fact that buds of a single tree were dissected. A more extensive application of bud-removal treatments at different stages of bud differentiation and parent shoot growth may contribute to our 
knowledge about the rules of preformation distribution among buds on the same parent shoot.

Neither of the treatments applied at the peak of offspring shoot growth altered the sums of diameters, lengths and numbers of nodes of all offspring shoots derived from the same parent shoot (compared to similar sums for control shoots), which indicates that the damage to a growing offspring shoot in $N$. dombeyi is fully compensated at the level of the parent shoot. On the other hand, clipping a complete distal offspring shoot at the peak of its extension period increased the length and number of nodes of another distal offspring shoot on the same parent shoot (experiment 3, treatment 4). As a consequence, this trauma, unlike less extensive ones applied in other treatments of the same experiment, increased the differences in length and number of nodes between the largest offspring shoot and the corresponding mean for all other offspring shoots relative to those of control parent shoots. This implies that the largest, most distal offspring shoot restricts the growth of more proximal shoots whether it is undamaged or partially-damaged; only a severe damage of the distal shoot allows one of the nearby shoots to grow longer (but not thicker) and with more nodes. The re-direction of resources to the development of the released shoot, might be involved, as shown for other woody plants $[2,27,48,54]$.

The increased growth of a distal shoot after the destruction of a nearby shoot at the peak of its growth may be a consequence of the capacity of vigorous $N$. dombeyi shoots to develop neoformed organs after the extension of those organs preformed in the bud from which the shoot derived $[39,40]$. Primary shoot growth by neoformation may be a relevant mechanism allowing plants to acclimate to environmental conditions of unpredictable occurrence [15, 39]. Neoformation would increase the length and number of nodes of shoots close to a damaged shoot. However, their basal diameter would not be affected, as the tissues involved in stem thickening (before secondary growth takes place) would complete their growth during the expansion of preformed organs, irrespective of neoformation production. As a result, severe damage to a growing shoot would cause undamaged nearby shoots to develop disproportionately more in length and number of nodes than in stem thickness, which may have consequences on the released shoot's responses to bending stresses from self-weight or wind [55].

Leaf removal in Quercus robur and Q. petraea (Fagaceae family) during the shoot extension period stimulated the further growth of the shoot through the development of a second flush of growth from the terminal bud [7, 11]. Leaf removal from growing shoots of $N$. dombeyi did not increase the development of the treated shoots, which would indicate that the correlative inhibition exerted by leaves on terminal and axillary buds is not to be regarded as a general mechanism regulating axis growth. The different responses found on Quercus spp. as compared to those reported here for $N$. dombeyi might relate to the degree of specificity in the response of trees to leaf damage or be due to ontogenetic differences, since the studies on Quercus concerned seedlings and the present study dealt with older trees.

\subsection{Damage at bud-break}

The artificial clipping of the distal end of a parent shoot by the time of breaking of its buds (experiment 2) affected nega- tively both the sums of the sizes of all offspring shoots developed and the size of the largest offspring shoot relative to that of other offspring shoots (Figs. 4 and 5). The most distal offspring shoots developed after the damage reached mean lengths and numbers of nodes slightly higher than those they would have reached had no damage occurred (compare with the mean length and number of nodes of offspring shoots in position 5 on control parent shoots, Fig. 3B), which may be interpreted as a partial compensation. No response in terms of stem diameter was detected. For $N$. dombeyi, the most distal branches at the beginning of their extension would exert only a minor effect on the size gradients of branches on a common parent shoot, in contrast with the results of studies on other species $[9,52]$.

\subsection{Damage at dormancy}

The interpretation of the results of artificial damage caused during winter dormancy (experiment 1) is complicated by the number of treatments applied and the degree of variation in the responses of shoots to each treatment. Clipping the four most distal buds or the whole distal end of the parent shoots selected for this study (treatments 1 and 2) resulted, after a spring-summer growth period, in sums of diameters, lengths and numbers of nodes of offspring shoots lower than those corresponding to parent shoots treated otherwise. A partial compensation was detected for parent shoots deprived of distal buds, as the distal offspring shoots developed from these shoots were longer and had more nodes than those developed in equivalent positions (i.e. from position 5 to the parent shoot's proximal end; Fig. 3A) by other parent shoots. The fact that a similar response was not observed in parent shoots whose distal buds and leaves had been removed suggests that leaves devoid of axillary bud may favour the development of offspring shoots arising from immediately more proximal nodes, perhaps by supplying them with resources or hormones [17]. A recent study indicates that leaf senescence in $N$. dombeyi implies the resorption of about half of the nitrogen content from leaves [16]. The removal of distal buds in this species might induce the senescence of their subtending leaves, thus increasing resource availability of nearby growing shoots. An alternative, but not exclusive, explanation could be that leaves devoid of axillary bud may contribute to the strength of the shoot as a resource sink and favour, as a consequence, the development of its branches. The results for the girdling treatment indicate that phloem-transported hormones would not be implicated in the size differences among offspring shoots. The winter removal of shoots close to the parent shoot did not affect the size and size gradient of its offspring shoots, which argues against the idea of competition for resources with neighbour shoots as a determinant of the branching pattern of a shoot [54].

\subsection{Conclusions}

A number of studies have emphasized the role of endogenous rules in the architecture of plants while recognising the effects of exogenous factors in the expression of these rules [1, $6,20,21,37]$. The series of experiments presented here indicate that some of the architectural features of a species might be more resilient to traumatic factors than others. For instance, the position of branches and the distal-to-proximal decreasing gradient 
of branch size found along most shoots of $N$. dombeyi exhibit high degrees of resilience to localised damage. On the other hand, compensatory responses to damage occurring during the extension period may increase size differences between proximal and distal branches on a parent shoot. These differences may arise either from damage to axillary buds and its effect on the preformation of nearby buds, or from severe damage to a distal branch and its effect on the growth of a nearby branch. It may be concluded from this study that the ratio between the size of the largest branch and the mean size of the other branches on a particular shoot of $N$. dombeyi depends on a number of factors such as the type of axis of the tree [45], the individual tree concerned, the kind of trauma affecting the shoot and the time of the year in which the trauma is caused.

Studying the effects of herbivory on woody plants through short-term studies on relatively small axis portions (i.e. shoots) has been considered unsuitable due to the slow responses to herbivory exhibited by woody plants [24]. However, morphological responses may be detected by selecting experimental units on architectural grounds.

Acknowledgements: A. Passo, S. Ghirardi, N. Seoane and P. de Brito provided useful support in fieldwork and the Administración de Parques Nacionales, Argentina, allowed work within the Nahuel Huapi National Park. We are indebted to D. Barthélémy and P. Heuret whose comments and suggestions contributed significantly to improve the manuscript. This study was supported by Universidad Nacional del Comahue (Project B096) and CONICET (PEI 0800/99), Argentina.

\section{REFERENCES}

[1] Barthélémy D., Caraglio Y., Costes E., Architecture, gradients morphogénétiques et âge physiologique chez les végétaux, in: Bouchon J., de Reffye P., Barthélémy D. (Eds.), Modélisation et simulation de l'architecture des plantes, INRA Editions, Science Update, Paris, 1997, pp. 89-136.

[2] Bergström R., Danell K., Effects of simulated winter browsing by moose on morphology and biomass of two birch species, J. Ecol. 75 (1987) 533-544.

[3] Bossdorf O., Schröder S., Prati D., Auge H., Palatability and tolerance to simulated herbivory in native and introduced populations of Alliaria petiolata (Brassicaceae), Am. J. Bot. 91 (2004) 856-862.

[4] Brown C.L., McAlpine R.G., Kormanik P.P., Apical dominance and form in woody plants: a reappraisal, Am. J. Bot. 54 (1967) 153162.

[5] Buck-Sorlin G.H., Bell A.D., Models of crown architecture in Quercus petraea and $Q$. robur: shoot lengths and bud numbers, Forestry 73 (2000) 1-19.

[6] Caraglio Y., Barthélémy D., Revue critique des termes relatifs à la croissance et à la ramification des tiges des végétaux vasculaires, in: Bouchon J., de Reffye P., Barthélémy D. (Eds.), Modélisation et simulation de l'architecture des plantes, INRA Editions, Science Update, Paris, 1997, pp. 11-87.

[7] Chaar H., Colin F., Leborgne G., Artificial defoliation, decapitation of the terminal bud, and removal of the apical tip of the shoot in sessile oak seedlings and consequences on subsequent growth, Can. J. For. Res. 27 (1997) 1614-1621.

[8] Chamberlin E.A., Aarsen L.W., The cost of apical dominance in white pine (Pinus strobus L.): growth in multi-stemmed versus single-stemmed trees, Bull. Torrey Bot. Club 123 (1996) 268-272.
[9] Champagnat P., Formation of the trunk in woody plants, in: Tomlinson P.B., Zimmerman H. (Eds.), Tropical trees as living systems, Cambridge Univ. Press, New York, 1976, pp. 401-422.

[10] Champagnat P., Rest and activity in vegetative buds of trees, Ann. Sci. For. 46 (1989) 9-26.

[11] Collin P., Badot P.-M., Millet B., Croissance rythmique et développement du chêne rouge d'Amérique, Quercus rubra L., cultivé en conditions contrôlées, Ann. Sci. For. 53 (1996) 1059-1069.

[12] Conti H.A., Características climáticas de la Patagonia, in: Correa M.N. (Ed.), Flora Patagónica VIII (I), INTA, Buenos Aires, 1998, pp. 31-47.

[13] Cornelissen J.H.C., Growth, morphology and leaf characteristics after simulated herbivory in Chinese subtropical evergreen saplings, Ecol. Res. 8 (1993) 143-150.

[14] Costes E., Reffye P. de, Lichou J., Guédon Y., Audubert A., Jay M., Stochastic modelling of apricot growth units and branching, Acta Hortic. 313 (1992) 89-98.

[15] Davidson C.G., Remphrey W.R., Shoot neoformation in clones of Fraxinus pennsylvanica in relation to genotype, site and pruning treatments, Trees 8 (1994) 205-212.

[16] Diehl P., Mazzarino M.J., Funes F., Fontenla S., Gobbi M., Ferrari J., Nutrient conservation strategies in native Andean-Patagonian forests, J. Veg. Sci. 14 (2003) 63-70.

[17] Eckstein R.L., Karlsson P.S., Weih M., Leaf life span and nutrient resorption as determinants of plant nutrient conservation in temperate-arctic regions, New Phytol. 143 (1999) 177-189.

[18] Fink S., The occurrence of adventitious and proventitious buds within the bark of some temperate and tropical trees, Am. J. Bot. 70 (1983) 532-542.

[19] Frey B.R., Lieffers V.J., Landhäusser S.M., Comeau P.G., Greenway K.J., An analysis of sucker regeneration of trembling aspen, Can. J. For. Res. 33 (2003) 1169-1179.

[20] Hallé F., Oldeman R.A.A., Essai sur l'architecture et la dynamique de croissance des arbres tropicaux, Masson, Paris, 1970.

[21] Hallé F., Oldeman R.A.A., Tomlinson P., Tropical trees and forests. An architectural analysis, Springer-Verlag, Berlin, 1978.

[22] Hatta H., Honda H., Fisher J.B., Branching principles governing the architecture of Cornus kousa (Cornaceae), Ann. Bot. 84 (1999) 183-193.

[23] Haukioja E., The influence of grazing on the evolution, morphology and physiology of plants as modular organisms, Phil. Trans. R. Soc. Lond. B 333 (1991) 241-247.

[24] Haukioja E., Koricheva J., Tolerance to herbivory in woody vs. herbaceous plants, Evol. Ecol. 14 (2000) 551-562.

[25] Haukioja E., Ruohomäki K., Senn J., Suomela J., Walls M., Consequences of herbivory in the mountain birch (Betula pubescens ssp. tortuosa): importance of the functional organization of the tree, Oecologia 82 (1990) 238-247.

[26] Heuret P., Barthélémy D., Nicolini E., Atger C., Analyse des composantes de la croissance en hauteur et de la formation du tronc chez le chêne sessile, Quercus petraea (Matt.) Liebl. (Fagaceae) en sylviculture dynamique, Can. J. Bot. 78 (2000) 361-373.

[27] Hjältén J., Danell K., Ericson L., Effects of simulated herbivory and intraspecific competition on the compensatory ability of birches, Ecology 74 (1993) 1136-1142.

[28] Honda H., Hatta H., Fisher J.B., Branch geometry in Cornus kousa (Cornaceae): computer simulations, Am. J. Bot. 84 (1997) 745-755.

[29] Horn H.S., The adaptive geometry of trees, Princeton University Press, Princeton, 1971.

[30] Loewe V., Toral M., Camelio M.E., López C., Monografía de coigüe, Nothofagus dombeyi, INFOR, CONAF, Santiago de Chile, 1997. 
[31] Marquis R.J., Lill J.T., Piccinni A., Effect of plant architecture on colonization and damage by leaftying caterpillars of Quercus alba, Oikos 99 (2002) 531-537.

[32] McCurdy W.D., Powell G.R., Syllepsis in Larix laricina: association of sylleptic branching with cross-sectional stem growth and stem form of saplings, Can. J. For. Res. 17 (1987) 1609-1619.

[33] McNaughton S.J., Compensatory plant growth as a response to herbivory, Oikos 40 (1983) 329-336.

[34] Milligan R.H., Insects damaging beech (Nothofagus) forests, Proc. New Zealand Ecol. Soc. 21 (1974) 32-40.

[35] Minitab, Data Analysis Software, standard version 7.1., State College Pennsylvania, Pennsylvania, 1989.

[36] Mutke S., Sievänen R., Nikinmaa E., Perttunen J., Gil L., Crown architecture of grafted Stone pine (Pinus pinea $\mathrm{L}$.): shoot growth and bud differentiation, Trees 19 (2005) 15-25.

[37] Nicolini E., Barthélémy D., Heuret P., Influence de la densité du couvert forestier sur le développement architectural de jeunes chênes sessiles, Quercus petraea (Matt.) Liebl. (Fagaceae), en régénération forestière, Can. J. Bot. 78 (2000) 1531-1544.

[38] Parker T., Johnson F.D., Branching and terminal growth of western red cedar, Northwest Sci. 61 (1987) 7-12.

[39] Puntieri J.G., Barthélémy D., Martinez P., Raffaele E., Brion C., Annual-shoot growth and branching patterns in Nothofagus dombeyi (Fagaceae), Can. J. Bot. 76 (1998) 673-685.

[40] Puntieri J.G., Pyšek P., Branching and competitive hierarchies in populations of Galium aparine, Can. J. Bot. 76 (1998) 63-74.

[41] Puntieri J.G., Raffaele E., Martinez P., Barthélémy D., Brion C., Morphological and architectural features of young Nothofagus pumilio (Poepp. et Endl.) Krasser (Fagaceae), Bot. J. Linnean Soc. 130 (1999) 395-410.

[42] Puntieri J.G., Souza M.S., Barthélémy D., Brion C., Núñez M., Mazzini C., Preformation, neoformation, and shoot structure in Nothofagus dombeyi (Nothofagaceae), Can. J. Bot. 78 (2000) 1044-1054.
[43] Puntieri J.G., Barthélémy D., Mazzini C., Brion C., Periods of organogenesis in shoots of Nothofagus dombeyi (Mirb.) Oerst. (Nothofagaceae), Ann. Bot. 89 (2002) 115-124.

[44] Puntieri J.G., Stecconi M., Barthélémy D., Preformation and neoformation in shoots of Nothofagus antarctica (G. Forster) Oerst. (Nothofagaceae) shrubs from northern Patagonia, Ann. Bot. 89 (2002) 665-673

[45] Puntieri J.G., Souza M.S., Brion C., Mazzini C., Barthélémy D., Axis differentiation in two South American Nothofagus species (Nothofagaceae), Ann. Bot. 92 (2003) 589-599.

[46] Raffaele E., Puntieri J.G., Martinez P., Marino J., Brion C., Barthélémy D., Comparative morphology of annual shoots in seedlings of five Nothofagus species from Argentinean Patagonia, C. R. Acad. Sci. 321 (1998) 305-311.

[47] Rousseaux C., Julkunen-Tiitto R., Searles P.S., Scopel A.L., Aphalo P.J., Ballaré C.L., Solar UV-B radiation affects leaf quality and insect herbivory in the southern beech tree Nothofagus antarctica, Oecologia 138 (2004) 505-512.

[48] Rust S., Hüttl R.F., The effect of shoot architecture on hydraulic conductance in beech (Fagus sylvatica L.), Trees 14 (1999) 39-42.

[49] Scoppa C.O., Los suelos, in: Correa M.N. (Ed.), Flora Patagónica VIII (I), INTA, Buenos Aires, 1998, pp. 15-30.

[50] Sokal R.R., Rohlf F.J., Biometry, 2nd ed., Freeman and Co., New York, 1981.

[51] Souza M.S., Puntieri J.G., Barthélémy D., Brion C., Bud content and its relation to shoot size and structure in Nothofagus pumilio (Poepp. et Endl.) Krasser (Nothofagaceae), Ann. Bot. 85 (2000) 547-555.

[52] Strauss S.Y., Agrawal A.A., The ecology and evolution of plant tolerance to herbivory, Trends Ecol. Evol. 14 (2003) 179-185.

[53] Watson M.A., Integrated physiological units in plants, Trends Ecol. Evol. 1 (1986) 119-123.

[54] Wilson B.F., Apical control of branch growth and angle in woody plants, Am. J. Bot. 87 (2000) 601-607.

[55] Wilson B.F., Archer R.R., Tree design: some biological solutions to mechanical problems, Bioscience 29 (1979) 293-298. 